\title{
Luomunurmen sadon ja apilapitoisuuden spatiaalinen vaihtelu
}

Arja Nykänen ${ }^{1)}$, Lauri Jauhiainen ${ }^{2)}$ ja Jukka Kemppainen ${ }^{3)}$

1) MTT, $51900 J u v a$, arja.nykanen@mtt.fi

${ }^{2)}$ MTT, 31600 Jokioinen, lauri.jauhiainen@mtt.fi

3) MTT, 88600 Sotkamo, jukka.kemppainen@mtt.fi

\section{Tiivistelmä}

Luonnonmukaisessa tuotannossa monivuotiset nurmet ovat tyypillisesti apila-heinä-seosnurmia. Punaapilapitoisten nurmien viljely on yleistynyt myös tavanomaisessa tuotannossa. Nurmien sadon määrä ja varsinkin apilapitoisuus vaihtelee pellon sisällä suuresti, mutta vaihtelun suuruudesta ja nopeudesta ei tiedetä vielä paljonkaan. Tätä vaihtelua haluttiin selvittää ja samalla haluttiin ottaa käyttöön ns. spatiaalitekniikka tilastollisena tutkimusmenetelmänä.

Tutkimus toteutettiin Juvalla ja Sotkamossa noin kahden hehtaarin kokoisella peltolohkolla. Juvan pelto on ollut luomuviljelyssä 20 vuotta ja Sotkamon pelto siirtyi luonnonmukaiseen tuotantoon kokeen alkaessa vuonna 2003. Puna-apila-timotei-ruokonata nurmet perustettiin ohra suojaviljaan ja lannoitettiin naudan lietelannalla. Peltolohkoille sijoitettiin 100 (Sotkamo) tai 105 (Juva) $15 \mathrm{~m}^{2}$ ruutua, joista korjattiin kaksi nurmisatoa vuodessa 2004-2005. Sadoista määritettiin kuiva-ainesadot ja niiden apilapitoisuudet. Näiden ominaisuuksien spatiaalinen eli pinnanmyötäinen vaihtelu pellolla tutkittiin käyttäen mallipohjaista spatiaalista interpolointia (kriging). Ennen interpolointia spatiaalinen riippuvuus mallitettiin variogrammin avulla tilastollisten ohjelmien avulla.

Peltojen sisäinen sadon määrän vaihtelu oli erittäin suurta molemmilla pelloilla. Juvalla vaihteluväli oli $1800-4000 \mathrm{~kg} \mathrm{ha}^{-1}$ niittoa kohti ja Sotkamossa $2000-6000 \mathrm{~kg} \mathrm{ha}^{-1}$. Juvalla oli havaittavissa satjen laskua toisena nurmivuonna, mitä ei Sotkamon pellolla vielä tapahtunut.Nurmisatojen spatiaalinen riippuvuus eli saadut variogrammit olivat hyvin samanlaisia molempina nurmivuosina. Nurmisatojen spatiaalinen riippuvuus kesti noin 50 metriin saakka. Huomattavaa oli, että spatiaalinen riippuvuus heikentyi aika pieneksi jo, kun etäisyys kasvoi 20-30 metriin, jolloin sopiva näytteenottoväli sadon määrittämiseksi olisi 30-50 metriä.

Nurmien apilapitoisuudet vaihtelivat $0-100 \%$ kuiva-aineesta molemmilla koepaikoilla ja molemmissa niitoissa vuonna 2004. Keskimääräinen apilapitoisuus oli Juvalla 45-65\%. Spatiaalinen riippuvuus katoaa kentillä 30-50 metrissä eli jos apilapitoisuutta haluaa määrittää omalta pelloltaan, täytyy näytteitä ottaa satoakin tiheämmin eli jopa alle 20 metrin välein.

Paikkatiedon huomioiminen auttaa ymmärtämään pellolla esiintyvää vaihtelua. Olennaista on tunnistaa ne tekijät, jotka aiheuttavat vaihtelun. Potentiaalisia vaihtelun aiheuttajia ovat maaperätekijät ja sääolosuhteet. Nyt saatujen tulosten perusteella voidaan todeta, että pelkät sääolosuhteet ja niiden yhdysvaikutukset pellolla esiintyvien muiden tekijöiden kanssa eivät selitä kuin pienen osan pellolla esiintyvästä vaihteluista. Tutkimuksen tieto auttaa valitsemaan $\mathrm{mm}$. näytteenottokohdat pellolta, kun nurmen apilapitoisuutta tai sadon määrää halutaan arvioida pellolta otettavilla näytteillä.

Avainsanat: puna-apila, seosnurmi, sato, apilapitoisuus, spatiaalinen vaihtelu 


\section{Johdanto}

Luonnonmukaisessa tuotannossa monivuotiset nurmet ovat tyypillisesti apila-heinä-seosnurmia. Punaapilapitoisten nurmien viljely on yleistynyt myös tavanomaisessa tuotannossa, koska nurmi tuottaa satoa pienemmällä typpilannoituksella apilan biologisen typensidonnan vuoksi, se pidentää nurmen korjuuaikaa ja on hyvä rehukasvi myös eläinten ruokinnassa. Nurmien sadon määrä ja varsinkin apilapitoisuus voi vaihdella pellon sisällä suuresti. Viljelijä tarvitsee tietoa nurmen apilapitoisuudesta ja sadon määrästä, kun hän laskee tilalleen typpitaseita. Myös eläinten ruokinnan kannalta o nurmen apilapitoisuus hyvä tietää. Pellon viljelytoimenpiteitä voi myös ajatella sen mukaan, kun tietää kuinka nurmi ja apila kasvaa eri puolilla peltoa ja eri peltolohkoilla.

Tätä vaihtelua haluttiin kartoittaa nyt esiteltävällä tutkimuksella. Tutkimuksen tieto auttaa valitsemaan mm. näytteenottokohdat pellolta, kun nurmen apilapitoisuutta tai sadon määrää halutaan arvioida pellolta otettavilla näytteillä.

Tutkimus kuuluu MMM:n rahoittaman Luomututkimusohjelman projektiin 'Puna-apila tehokkaasti luomumaidoksi'.

\section{Aineisto ja menetelmät}

\section{Koepellot ja nurminäytteet}

Tutkimus suoritettiin Juvalla MTT Ekologisen tuotannon tutkimusaseman ja Kainuun tutkimusaseman pelloilla vuosina 2004 ja 2005. Juvan pelto on maalajiltaan moreenia ja ollut luomuviljelyssä 20 vuotta. Kainuun pelto puolestaan hiesuista hienoa hietaa tai karkeaa hietaa ja oli luomun siirtymävaiheessa vuonna 2004. Pellot ovat noin kahden hehtaarin suuruisia ja niille on sijoiteltu Juvalla 105 ja Sotkamossa 100 pienempää ruutua, joiden koko oli 1,5 x 10 metriä. Koeruudut sijoitettiin mahdollisimman tasaisesti ympäri peltoa, jotta tutkittavasta ominaisuuden vaihtelusta pellon sisällä saadaan mahdollisimman tarkka kuva. Spatiaalisen riippuvuuden tutkimisen kannalta olennaista on, että pellolta löytyy riittävästi 2-10 metrin etäisyydellä toisistaan olevia koeruutuja. Jotta kumpikin ehdoista täyttyi, pelto jaettiin ensin $30 \times 30 \mathrm{~m}$ kokoisiin isoihin ruutuihin. Ison ruudun sisälle sijoitettiin 3-5 pikkuruutua, joista varsinaiset määritykset tehtiin. Etukäteen suunniteltiin erilaisia 3-5 pikkuruudun ryhmiä siten, että niiden avulla pystytään määrittämään spatiaalinen riippuvuus mahdollisimman tehokkaasti.

Pellolla kasvaa vuonna 2003 perustettu apilanurmi, jossa on puna-apilaa, timoteitä ja ruokonataa (lajikkeet Bjursele, Iki ja Retu, kylvöseos 3-19-6 kg ha ${ }^{-1}$ ). nurmet perustettiin ohra suojakasvina ja ne lannoitettiin Juvalla ilmastetulla naudan lietelannalla ja Sotkamossa kuivikelannalla keväällä 2003 ennen kylvöjä.

Ruuduilta korjattiin sato kaksi kertaa vuodessa Haldrup -korjuukoneella, joka punnitsi ruutukohtaisen sadon pellolla. Ensimmäinen sato korjattiin touko-kesäkuun vaihteessa ja toinen sato syyskuun alussa. Nurminäytteistä määritettiin sadon kuiva-ainepitoisuus kuivaamalla yön yli 105 asteessa ja sen avulla laskettiin kuiva-ainesadot. Nurmen apilapitoisuus määritettiin NIRSanalysaattorilla 60 asteessa yön yli kuivatuista ja jauhetuista näytteistä (Nykänen et al 2006a). Juvan ruuduilta määritettiin vuonna 2003 ravinnepitoisuudet sekä myös maan mikrobiologisia ominaisuuksia (Nykänen \& Jauhiainen 2005, Nykänen et al. 2006b).

\section{Tilastollinen käsittely}

Mitattujen tekijöiden vaihtelu pellolla tutkittiin käyttäen mallipohjaista spatiaalista interpolointia (kriging). Tämän menetelmän avulla voidaan tutkittavan ominaisuuden arvo interpoloida pellon jokaiseen pisteeseen, vaikka se olisi alun perin mitattu vain tietyistä kohdin peltoa. Muihin interpolointimenetelmiin verrattuna valittu menetelmä tuottaa arvon lisäksi sille keskivirheen. Keskivirhe kuvaa saadun arvon tarkkuutta, mikä on hyödyllinen tieto arvioitaessa sitä, kuinka tiheästi ominaisuuden arvo tulisi pellolta mitata, jotta koko pellosta saataisiin hyvä kuva. Ennen interpolointia spatiaalinen riippuvuus mallitettiin variogrammin avulla. Tilastolliset analyysit tehtiin SAS-ohjelmiston VARIOGRAM-, NLIN- ja KRIGE2D-proseduureilla. 


\section{Tulokset ja tulosten tarkastelu}

\section{Nurmisadot}

Peltojen sisäinen sadon määrän vaihtelu oli erittäin suurta molemmilla pelloilla. Juvalla vaihteluväli oli vuonna 2004 vähän yli $4000 \mathrm{~kg} \mathrm{ha}^{-1}$ ja vuonna 2005 ensimmäisessä niitossa 3300 ja toisessa niitossa $1800 \mathrm{~kg} \mathrm{ha}^{-1}$. Sotkamossa puolestaan ensimmäisessä niitossa vaihtelu oli 5 000-6 $000 \mathrm{~kg} \mathrm{ha}^{-1}$ ja toisessa niitossa $2000 \mathrm{~kg} \mathrm{ha}^{-1}$ molempina vuosina. (Taulukko 1).

Kuiva-ainesadot vuonna 2004 Juvan pellolla olivat keskimäärin $4700 \mathrm{~kg} \mathrm{ha}^{-1}$ molemmissa niitoissa ja vuonna 2005 ensimmäisessä niitossa $3400 \mathrm{~kg} \mathrm{ha}^{-1}$ ja toisessa niitossa $1600 \mathrm{~kg} \mathrm{ha}^{-1}$. Sotkamon pellolla vuonna 2004 ensimmäisen niiton kuiva-ainesadot olivat keskimäärin 5300 ja toisessa niitossa $1300 \mathrm{~kg} \mathrm{ha}^{-1}$. Vuoden 2005 sadot olivat vastaavasti $5600 \mathrm{ja} 1500 \mathrm{~kg} \mathrm{ha}^{-1}$. (Taulukko 1). Näiden lukujen perusteella Juvalla olisi havaittavissa satotason laskua toisena satovuonna. Kainuussa puolestaan kiinnittää huomiota suuri ero ensimmäisen ja toisen niiton välillä. Tämä johtunee siitä, että ensimmäinen niitto tehtiin suhteellisen myöhään, reilusti heinäkuun puolella, kun se Juvalla tehtiin ennen tai jälkeen juhannuksen.

Nurmisatojen spatiaalinen riippuvuus eli saadut variogrammit olivat hyvin samanlaisia molempina nurmivuosina ja erot peltojen välillä olivat myös pienet. Juvalla nurmisatojen spatiaalinen riippuvuus kesti aina 50-60 metriin saakka ja Sotkamossakin 40-50 metriin molempina vuosina (Taulukko 1). Tämä tarkoittaa, että yhdestä paikasta mitattu sato ennustaa edes jossain määrin satoa jopa 60 metriin saakka. Huomattavaa oli, että spatiaalinen riippuvuus heikentyi aika pieneksi jo, kun etäisyys kasvoi 20-30 metriin. Tämä johtui siitä, ettei korrelaatio pienentynyt lineaarisesti etäisyyden kasvaessa vaan nopeimmin pienillä etäisyyksillä. Näin ollen mitatun yksittäisen satoarvon ennustetarkkuus 30 metrin päässä olevan kasvuston satotasoon oli tässä tutkimuksessa jo niin pieni, että näytteitä tulisi ottaa pelloilta noin 30-50 metrin välein, jotta saisi luotettavan arvion sadon määrästä kyseisellä pellolla.

Taulukko 1. Nurmien kuiva-ainesadot (kg/ha) sekä niiden spatiaaliset riippuvuudet (m) Juvan ja Sotkamon kentillä.

\begin{tabular}{|c|c|c|c|c|c|c|c|c|}
\hline & $\begin{array}{l}\text { Juva } \\
2004 \\
\text { Sato 1 }\end{array}$ & Sato 2 & $\begin{array}{l}2005 \\
\text { Sato } 1\end{array}$ & Sato 2 & $\begin{array}{l}\text { Kainuu } \\
2004 \\
\text { Sato 1 }\end{array}$ & Sato 2 & $\begin{array}{l}2005 \\
\text { Sato } 1\end{array}$ & Sato 2 \\
\hline Keskiarvo & 4821 & 4887 & 3432 & 1607 & 5200 & 1251 & 5495 & 1552 \\
\hline Mediaani & 4677 & 4816 & 3368 & 1563 & 5311 & 1255 & 5616 & 1524 \\
\hline Min & 2799 & 2572 & 2016 & 876 & 2305 & 317 & 2190 & 540 \\
\hline Maks & 7271 & 6768 & 5354 & 2602 & 7322 & 2282 & 8299 & 2609 \\
\hline Spat riippuvuus & 60 & 60 & 50 & 60 & 42 & 47 & 52 & 40 \\
\hline
\end{tabular}

\section{Nurmien apilapitoisuudet}

Nurmien apilapitoisuudet vaihtelivat $0-100 \%$ kuiva-aineesta molemmilla koepaikoilla ja molemmissa niitoissa vuonna 2004. Keskimääräinen apilapitoisuus oli Juvalla $45-50 \%$ ja Sotkamossa $55-65 \%$ (Taulukko2). Yleensä on ollut havaittavissa, että toisen niiton sadon apilapitoisuus on korkeampi kuin ensimmäisen niiton, näiden tulosten perusteella ei näillä pelloilla tilanne ollut sama. Spatiaalinen riippuvuus katoaa kentillä 30-50 metrissä eli jos apilapitoisuutta haluaa määrittää omalta pelloltaan, täytyy näytteitä ottaa noin satoakin tiheämmin eli jopa alle 20 metrin välein.

Taulukko 2. Nurmien apilapitoisuudet (\% kuiva-aineesta) sekä niiden spatiaaliset riippuvuudet (m) Juvan ja Sotkamon kentillä.

\begin{tabular}{|c|c|c|c|c|}
\hline & $\begin{array}{l}\text { Juva } \\
2004 \\
\text { Apila 1 }\end{array}$ & Apila 2 & $\begin{array}{l}\text { Kainuu } \\
2004 \\
\text { Apila 1 }\end{array}$ & Apila 2 \\
\hline Keskiarvo & 46,1 & 48,4 & 52,5 & 67,0 \\
\hline Mediaani & 46,2 & 50,0 & 53,4 & 65,3 \\
\hline Min & 0,0 & 0,3 & 0,0 & 33,5 \\
\hline Maks & 99,3 & 89,0 & 99,8 & 99,9 \\
\hline
\end{tabular}


\begin{tabular}{|l|l|l|l|l|} 
Spat riippuvuus & 29 & 44 & 54 & 38 \\
\hline
\end{tabular}

\section{Spatiaalinen vaihtelu}

Nurmisatojen spatiaalista vaihtelua kuvaavat kartat on esitetty kuvissa 1 ja 2 . Juvalla molempina vuosina ensimmäisen ja toisen niiton kuviot ovat hyvin samannäköiset. Vuosien 2004 ja 2005 välillä on kuitenkin tapahtunut pientä muutosta, sillä suurimmat sadot etenkin toisessa niitossa ovat vuonna 2004 olleet enemmän pellon vasemmassa reunassa kuin vuonna 2005. (Kuva 1). Koska satotaso toisessa niitossa on ollut pienempi kuin ensimmäisessä ja erot alueiden välillä siten myös pienemmät, kokonaissadon osalta ero vuosien 2004 ja 2005 välillä ei kuitenkaan ole kovin suuri.
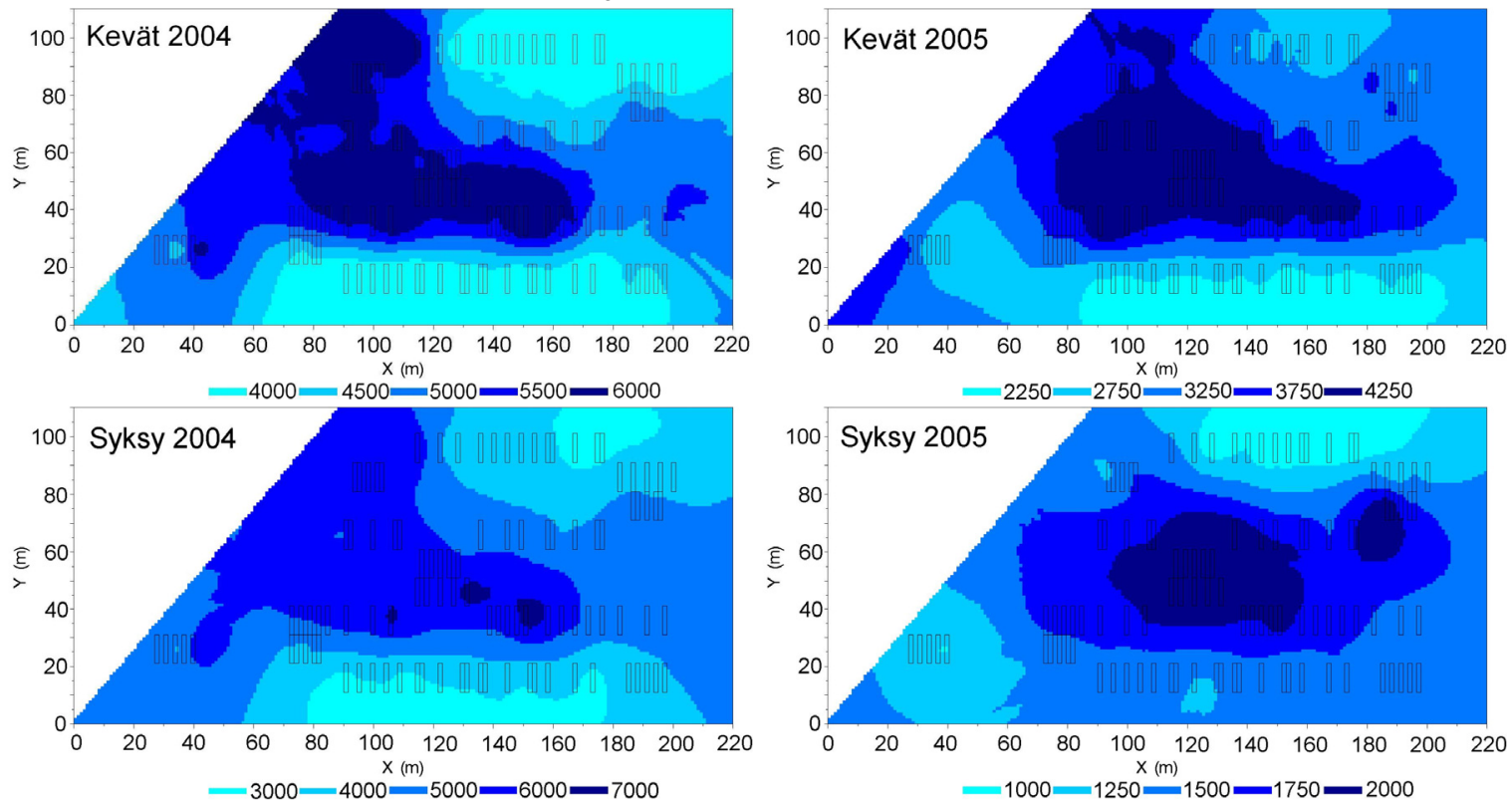

Kuva 1. Nurmien kokonaiskuiva-ainesatojen $\left(\mathrm{kg} \mathrm{ha}^{-1}\right.$, ensimmäinen ja toinen niitto yhteensä) spatiaalinen vaihtelu pellolla Juvalla vuosina 2004 ja 2005

Sotkamossa vuonna 2004 ei ensimmäisen ja toisen niiton välillä ollut havaittavissa suurta eroa satomäärien spatiaalisessa vaihtelussa eli samat alueet tuottivat matalan sadon kummassakin niitossa. Vuonna 2005 tulokset osoittavat, että toisen sadon määrät kompensoivat ensimmäisen niiton satomääriä. Jos sato ensimmäisessä niitossa on ollut suhteellisesti korkea pellon muihin osiin verrattuna, on se monessa kohdassa ollut toisessa niitossa vastaavasti pienempi. Mielenkiintoista on, että samalla pellolla voi tällaista kompensointia esiintyä molempiin suuntiin. 

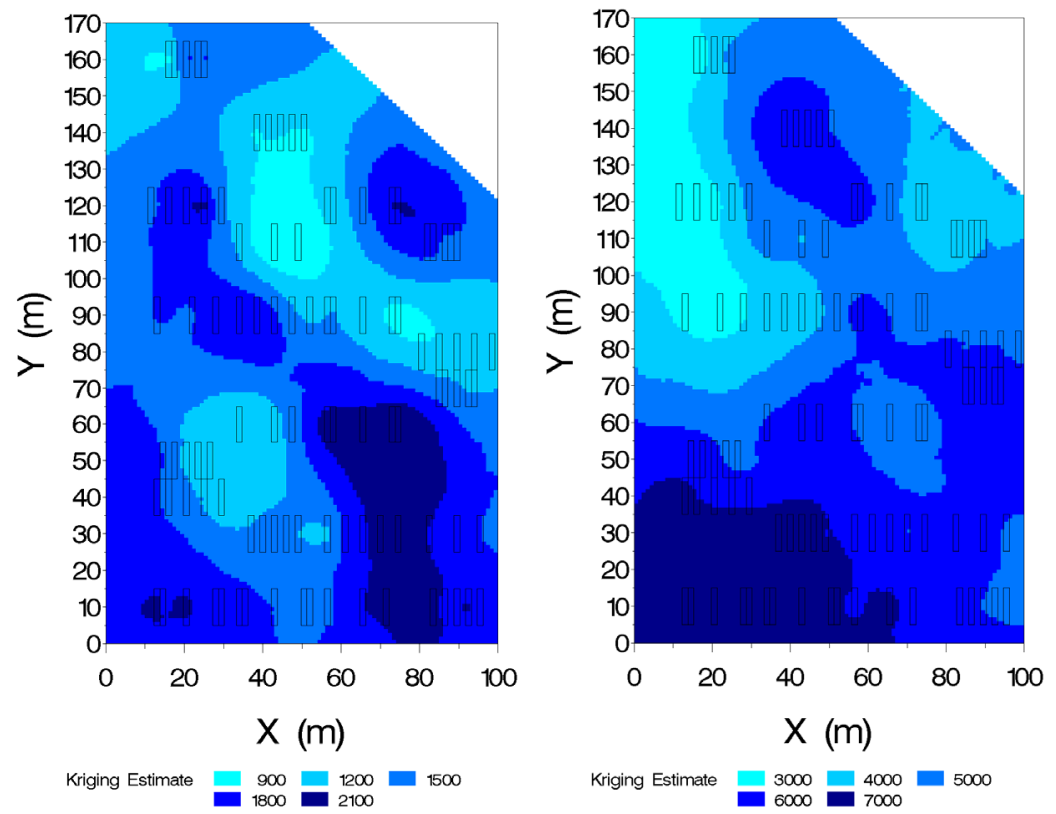

Kuva 2. Nurmisatojen $\left(\mathrm{kg} \mathrm{ha}^{-1}\right.$, ka) spatiaalinen vaihtelu Sotkamossa vuonna 2005 ensimmäisessä ja toisessa niitossa.

Nurmisatojen apilapitoisuudet on analysoitu vasta vuoden 2004 sadoista. Juvalla ensimmäisen niiton apilapitoisuuksissa oli selkeä laskeva trendi 70\%:sta 30\%:n tasoon, kun pellolla siirryttiin vasemmasta alakulmasta oikeaan yläkulmaan eli ylärinteeseen. Toisessa niitossa tätä ei enää ollut havaittavissa. (Kuva 3.) . Sotkamon kenttä oli apilapitoisuuksien osalta hyvin epähomogeeninen ensimmäisessä niitossa, kun taas toisessa niitossa se oli paljon homogeenisempi lähestyen kauttaaltaan $70 \%$ tasoa. (Kuva 4).
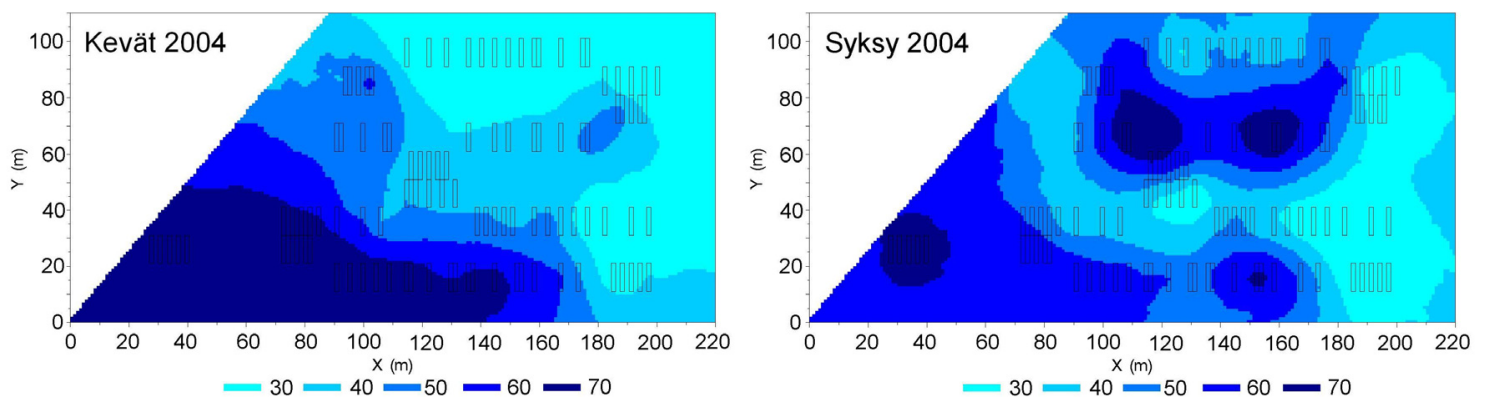

Kuva 3. Nurmisatojen apilapitoisuuksien spatiaalinen vaihtelu (\% kuiva-ainesadosta) Juvan kentällä vuonna 2004 ensimmäisessä ja toisessa niitossa. 

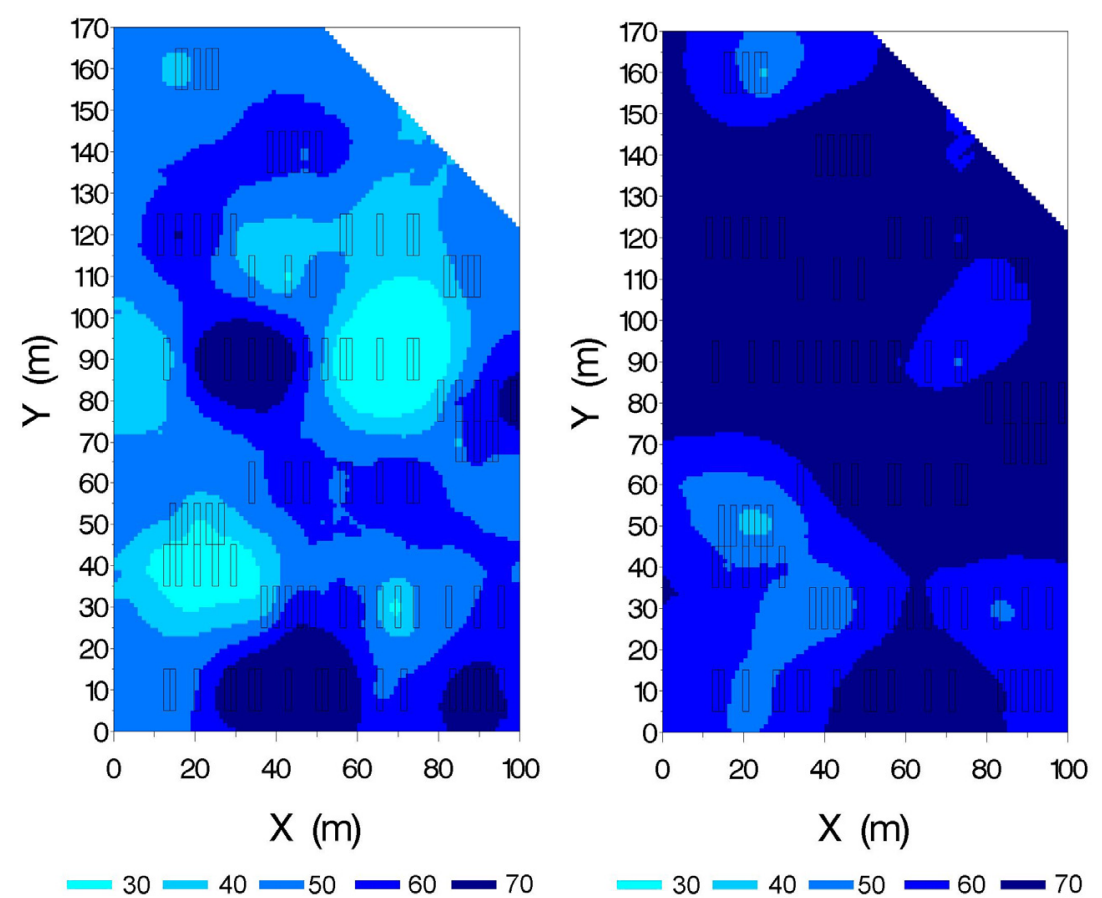

Kuva 4. Nurmisatojen apilapitoisuuksien spatiaalinen vaihtelu (\% kuiva-ainesadosta) Sotkamon kentällä vuonna 2004 ensimmäisessä ja toisessa niitossa.

\section{Johtopäätökset}

Peltojen sisäinen sadon määrän vaihtelu oli erittäin suurta molemmilla pelloilla. Juvalla vaihteluväli oli 1 800- $4000 \mathrm{~kg} \mathrm{ha}^{-1}$ niittoa kohti ja Sotkamossa $2000-6000 \mathrm{~kg} \mathrm{ha}^{-1}$. Juvalla oli havaittavissa satojen laskua toisena nurmivuonna, mitä ei Sotkamon pellolla vielä tapahtunut.Nurmisatojen spatiaalinen riippuvuus eli saadut variogrammit olivat hyvin samanlaisia molempina nurmivuosina. Nurmisatojen spatiaalinen riippuvuus kesti noin 50 metriin saakka. Huomattavaa oli, että spatiaalinen riippuvuus heikentyi aika pieneksi jo, kun etäisyys kasvoi 20-30 metriin, jolloin sopiva näytteenottoväli sadon määrittämiseksi olisi 30-50 metriä.

Nurmien apilapitoisuudet vaihtelivat $0-100 \%$ kuiva-aineesta molemmilla koepaikoilla ja molemmissa niitoissa vuonna 2004. Keskimääräinen apilapitoisuus oli Juvalla 45-65\%. Spatiaalinen riippuvuus katoaa kentillä 30-50 metrissä eli jos apilapitoisuutta haluaa määrittää omalta pelloltaan, täytyy näytteitä ottaa satoakin tiheämmin eli jopa alle 20 metrin välein.

Paikkatiedon huomioiminen auttaa ymmärtämään pellolla esiintyvää vaihtelua. Olennaista on tunnistaa ne tekijät, jotka aiheuttavat vaihtelun. Potentiaalisia vaihtelun aiheuttajia ovat maaperätekijät ja sääolosuhteet. Nyt saatujen tulosten perusteella voidaan todeta, että pelkät sääolosuhteet ja niiden yhdysvaikutukset pellolla esiintyvien muiden tekijöiden kanssa eivät selitä kuin pienen osan pellolla esiintyvästä vaihteluista. Muut mahdolliset selittäjät kuten maaperän erilaiset biologiset ja kemialliset ominaisuudet ovat potentiaalisia vaihtelun selittäjiä. Tutkittavilta peltolohkoilta on mitattu myös näitä ominaisuuksia ja niiden yhteyttä satovaihteluihin tullaan tutkimaan jatkossa. Tähän mennessä tehty työ ja suunnitellut jatkotarkastelut ovat tärkeitä ja helpottavat erityisesti seosnurmien kanssa töitä tekevien tutkijoiden työtä.

\section{Kirjallisuus}

Nykänen, A. \& Jauhiainen, L. 2005. Maan ravinnepitoisuuksien spatiaalinen vaihtelu luomumoreenipellolla. Pro Terra 22: 187-188.

Nykänen, A., Jauhiainen, L. \& Palojärvi, A. 2006. Maan mikrobiologisten ominaisuuksien spatiaalinen vaihtelu luomumoreenipellolla. Maataloustieteenpäivät 2006. www.smts.fi

Nykänen, A., Kurri, O. ja Kemppainen, J. 2006. Seosnurmen apilapitoisuuden määritys NIRS-analysaattorilla kuivatusta näytteestä. Maataloustieteenpäivät 2006. www.smts.fi 